resulted in conviction. This is in marked contrast to the results in Worcester County in the few years last past. In the only 4 cases actually tried there within the last ten years, the principals were convicted in three and in the fourth he defaulted his bond. In the same cases four accessories were convicted and sentenced. One accessory was acquitted, and as to one other the jury disagreed.

In Massachusetts it is not a crime for a woman - to commit an abortion upon herself nor to submit to one by another. She is here regarded rather as the victim. The law is otherwise $\mathrm{n}$ England and in about a dozen of the states. (Reg. $v$. Fretwell, 9 Cox. C. C. 152; People $v$. Mayers, 5 N. Y. A. R. 120.) This failure of the Massachusetts statute to make criminal the act of the woman in consenting to the operation has been frequenty criticised. But her immunity sometimes renders possible the conviction of the abortionist. When she survives the operation the abortionist may be convicted upon her testimony alone (or now upon her dying declaration alone, in case of death), while if she were regarded as an accomplice in the crime, the rule of practice that a person may not be convicted on the uncorroborated testimony of an accomplice would prevent conviction where no other evidence was obtainable. (Com. v. Wood, 11 Gray, 85; Com. $v$. Follansbee, 155 Mass. 274.)

The subject of accessories is perhaps as important as that of principals in a discussion of this crime. It is seldom committed without the aid of accessories, either before or after the fact, and often both. The accessory before the fact is distinguished from the principal offender as one who, being absent at the time the felony is committed (to use the technical legal phraseology), "procures, counsels, commands or abets another to commit the felony." There is very often at least one accessory before the fact, sometimes the husband and sometimes the seducer. It is often a difficult question for the district attorney to determine how far it is wise to allow the accessory before the fact to turn state's evidence and thus render more certain the conviction of the abortionist. It would appear from the reported cases in Massachusetts that this policy had very often been followed.

But the more important consideration for the physician is that of accessory after the fact. He is one who, knowing a felony to have been committed by another, " receives, relieves, comforts or assists the felon." I have already referred to the subject of the physician's professional duty and duty to society upon making the discovery that a criminal abortion has been committed. I now refer to his legal rights merely. Of course he may take care of the victim, and he is under no legal obligation to disclose what he may discover or suspect regarding an abortion. He may keep silent without becoming a criminal. When, however, he does anything to prevent the detection or conviction of the abortionist, he becomes an accessory after the fact. If, for example, he destroys the fetus, which often furnishes evidence of the abortion, or if he destroys the catheter or other means used to procure the abortion, with intent to shield the abortionist, he becomes an accessory to the crime. Accessories may now be tried and convicted, before there has been any conviction of the principal, although such was not formerly the law. (Revised Laws, Chapter 215, Section 5.) When, however, the abortionist is unknown to the physician, his purpose being to shield an unknown principal, certain legal difficulties to a conviction arise.

The above are a few of the legal principles involved in this subject, and the scope of this paper is limited to a discussion of them. The important inquiry, however, is not how far the physician may go without becoming a criminal, but rather what his professional duty is upon discovering that a criminal abortion has been performed, a subject to which I again revert by way of suggestion for further discussion by those better able to undertake it. An examination of the cases tried in Worcester County for several years last past reveals the fact that there has been only one trial where the woman has not died in consequence of the operation. (John W. Snow, of Athol, 1878.) Doubtless the greater part of the criminal abortions not resulting in death are never known to any physician. And yet the great rarity of prosecutions in such cases as compared with those where death results points to the conclusion that physicians make the disclosure in case of death and keep the secret when the victim recovers.

In Massachusetts, the confidential disclosures made by a patient to a physician are not privileged; that is, the physician may be compelled to testify to them in court. In about one half of the states the law is otherwise, though in such states it is the privilege of the patient and not of the physician, and the patient may waive the privilege.

\section{FIBROID PHTHISIS IN CHILDHOOD WITH PRESENTATION OF A CASE.*}

BY ARTHUR WILIAARD FAIRBANKS, M,D., BOSTON.

IT would be more accurate, I think, if I had termed the subject of my paper to-night " chronic interstitial pneumonia," for the causes of this condition are multiple and the tubercular organism but an occasional directly exciting factor. However, as the main interest lies rather in the presentation of a case, which I believe to be unquestionably of tubercular origin, than in my presentation of a paper on the subject in general, I have chosen the title of "fibroid phthisis." I would suggest, however, the elimination of this term as appliet to this rather typical process and the substitution of the term "tubercular interstitial pneumonia," as this term accurately and concisely describes, on the one hand, the process, and, on the other, the cause of the process in certain individual instances. The characteristic and essential feature of the pathological process is the proliferation of interstitial tissue, and that interstitial tissue may be interalveolar or inter-

* Read before the New England Pediatric Society, Nov. 28, 1908. 
lobular. The factor that makes the disease a well-marked clinical entity is the widespread character of this interstitial proliferation. Many processes in the pulmonary tissue are accompanied or followed by circumscribed increase of connective tissue, but this disease is a diffuse proliferation of this tissue, involving one entire lobe or one lung. The process is almost invariably apparently secondary to some preceding affection. I say, apparently, because it is not yet evident why these preceding affections should be followed in one case by this strikingly marked proliferation of interstitial tissue and in another not, for the antecedent conditions are all of frequent occurrence and only relatively very infrequently followed by any such pathological condition as that we are studying, at least in sufficient degree to be clinically recognizable. Among these apparent exciting factors are antecedent lobar and lobular pneumonia, long-continued bronchitis, especially that accompanying measles, pertussis and influenza, and long-continued pleurisies, either with or without exudate. Many theories have been evolved to explain why these exceedingly common conditions should in one instance be followed by the affection under consideration, while in 999 others no such result ensues. Of the theories evolved, the most plausible and, at the same time, the most difficult one to prove is the assumption of an individual predisposition to excessive interstitial connective tissue formation in the exceptional instances in which the affection occurs. This is the theory fathered by Handfield Jones, in England, in 1854, and fostered by Beneke, in Germany, in 1881, and Sutton, Clark, Hadley and Chaplin, in England. As already said, this is an exceedingly convenient and even fairly rational explanation, but it is pure hypothesis and incapable of proof and it does not appear, as one might suppose, that individuals manifesting this tendency in pulmonary tissue are at the same time victims of indurative processes in other organs; that they are afflicted with interstitial nephritis, fibrous hepatitis, arteriosclerosis or sclerotic processes in the central nervous system, or anywhere else except in the lungs. Moreover, pneumonia in its various forms, long-continued bronchitis and pleurisy are frequent occurrences in the interstitial form of Bright's disease, in arteriosclerosis and in individuals presenting interstitial proliferation elsewhere, and yet these pulmonary processes show no greater tendency to be followed by chronic induration of the lung than when they occur in individuals not so afflicted. It is a poor rule that will not work both ways. In recognition of this fact some have tried to attribute the occurrence to syphilis or alcohol. Were these factors of any universal importance in the etiology of this affection it would be one of the most common of all clinical occurrences. When syphilis causes, as it may, an induration of pulmonary tissue, it is simply as a direct exciting cause and not as a predisposing factor. It is, in other words, merely a syphilitic interstitial pneumonia, just as we may have a tubercular, an influenzal, a streptococcic interstitial Nearly all of these phenomena have been seen pneumonia or pneumonitis, and when we have made such a diagnosis we are no nearer the explanation of why one syphilitic individual should have it and another should not than we were before. We do not know why it occurs in one case and not in another.

Like other proliferated connective tissue this in the lung manifests a tendency to contract, and it is the results of this contraction that produce the characteristic clinical features of the disease. In the first place, the contraction of the pulmonary tissue results in diminished expansion of the lung and hence restricted movement of the affected side. This is evident quite early in the process. As the contraction increases there gradually ensues not merely lessened excurs:on on that side, but actual retraction of the chest wall, the so-called "rétrécissement" of Laennec. This progressive contraction of one half of the thorax is followed by curvature of the thoracic spine to the side of the lesion and a varying degree of compensatory curvature of the lumbar spine in the opposite direction. As the process advances the pulmonary vesse's become involved in the proliferating and contracting connective tissue. As vessel after vessel becomes narrowed and finally obliterated the right heart responds to the increased resistence in the pulmonary circuit by gradual hypertrophy, interrupted from time to time by dilatation due to temporary dynamic weakness of the heart muscle, either inherent or secondary to some intercurrent disease, and this dilatation may be accompanied by the usual secondary results, cyanosis, edema, passive congestion of liver, kidneys and spleen and exudates in serous cavities. This condition is also seen in the terminal stage of the disease. Besides these general phenomena there are local conditions directly secondary to the advancing retraction of the affected portion of the lung and to the compensatory hypertrophy of the rest of the pulmonary tissue. These two occurrences cause displacement of other organs. The heart, for instance, is not only hypertrophied, but it is frequently displaced. This displacement is toward the contracted lung; that is, upward and to the left, as in this child; or upwards and to the right when the lesion is on that side. This dislocation of the heart is due in part to direct pleuro-pericardial adhesion, in part to the enlargement of the unaffected lung which entrenches upon the mediastinum and forces the heart to one or the other side. Not only may the heart be displaced, but its area appears increased or diminished according to whether the pulmonary process is on the left or the right. If on the left, the retracting lung uncovers a larger area of the heart and the area of absolute dullness is increased. If the right lung is affected, the compensatory hypertrophy of the left lung covers more of the cardiac area than normally and the area of cardiac dullness is diminished, or, as usually happens, entirely obliterated although the heart is actually hypertrophied. Either liver or spleen may be 
in this child at one time or another in the course of the affection, and many of them he presents at the present time in typical manner. You will notice the marked thoracic asymmetery, the curvature of the spine, the diminished excursion of the affected side, the increased volume of the unaffected lung with its pronounced hyper-resonance; the heart displaced upward and to the left, with the apex impulse in the third interspace and the downward displacement of the liver, the light but definite cyanosis and the increase in the cardiac area due in part to hypertrophy, in part to uncovering of the area by the shrunken left lung.

In addition to the above-enumerated features of the disease, percussion over the affected lung shows marked dullness over the entire left lung, but especially over the lower two thirds. Auscultation shows diminished respiration and voice sounds below the fourth rib anteriorly and midscapular region posteriorly, with the exception of a small area in the anterior axillary line, where rather well-marked bronchophony is present, probably due to a dilated bronchus. Over the upper lobe respiration is bronchovesicular everywhere except above the scapular spine, where it is quite bronchial in character.

When this case first came under my observation he was four years old. He had a history of having had pneumonia when two years old and having had a cough ever since. A man in the same house died with pulmonary tuberculosis a year after the child had pneumonia.

The diagnosis of left-sided pleural effusion had been made and a needle introduced; this, notwithstanding the fact that resonance, although diminished, extended clear to the base, and respiration was also audible, although distant, and the half-moon space of Traube was not obliterated and the heart was not displaced.

It is needless to say that no fluid was obtained and the gentleman who made the diagnosis was obliged to recede from the positive ground he had assumed. The case at this period showed decided limitation in excursion of the left side of the thorax, but no deformity except a slight flattening with marked relative but no absolute dullness over the lower half of this side, with diminished but no absent respiration over the entire left lung, diminishing from above downward, and voice sounds were also diminished but not absent over the base. Over the entire right chest both respiration and resonance were moderately increased. The area of the heart was even then somewhat increased to the right: The apex was then in normal position. The respiration was slightly accelerated but only very slightly labored. No evidence of consolidation was present at this time, but a few moist râles were present over the left upper lobe. There was no sputum. The progress was extremely slow and he did fairly well except for an occasional attack of bronchitis of mild grade until he was six years old. At this time, four years ago, he went through a severe attack of bronchopneumonia, and consolidation of the entire left upper lobe ensued and tubercle bacilli appeared in the sputum. Severe though the acute pul- monary condition was, the chief danger of this attack was, as might naturally be expected, the failure of the heart, which required considerable elimination. He recovered, however, more rapidly than one would have expected from the diffuse process, but the signs of consolidation in the left upper lobe persisted for several weeks, gradually clearing until practically no trace was left except slight bronchophony above the left scapular spine. The tubercle bacilli disappeared from the sputum after a few days and long before the infiltration in this left upper lobe cleared. It is, of course: impossible to tell whether the bacilli came from this or from some other focus. It is on the appearance of these bacilli at that time that I base my conclusion that this case presents that form of chronic interstitial pneumonia implied by the term "fibroid phthisis." In no other way could his case be differentiated from other forms caused by other organisms. He recovered apparently entirely from this acute attack and has had practically no cough since. Not only this, but during the past three years he has been improving materially and the physical signs are not as pronounced as they were three years ago. During these last three years he has been placed under very fortunate conditions as regards his environment from the first of May until the first of November. For these seven months he has been on a house-boat in the harbor without coming ashore, and exposed to the freshest of air practically day and night.

It is impossible to forecast the prognosis of any individual case of the affection. We can only say that it is extremely chronic but may at any time be interrupted with fatal results by intercurrent disease or by cardiac failure. That its course may be extraordinarily chronic is evidenced by this case, which has been under observation six years and probably dates from the attack of pneumonia two years previously, which gives thus far a duration of eight years.

It teaches us that we should not be hasty in giving a hopelessly unfavorable prognosis because the physical signs are pronounced early in the course of the disease.

The occurrence of chronic tubercular fibrous induration of the lung in childhood is sufficiently unusual, I think, to warrant the report and exhibition of this case in a boy of ten years. It cannot be considered so rare that it may be regarded as a clinical curiosity, but in my personal experience with a large number of pulmonary cases in children I have seen no case with so long a duration.

This long duration of the process in this boy, the intercurrent bronchopneumonia with the appearance of tubercle bacilli in the sputum, with complete consolidation of the left upper lobe, four years ago, the subsequent disappearance of the bacilli and the consolidation, the relatively excellent recovery and present health of the child, notwithstanding the marked deformity produced by the fibroid process, render the case one of considerable clinical and practical interest. With this child dressed and playing on the street 
one would not suppose that there was anything the matter with him except that possibly the more critical might note a moderate cyanosis.

\section{DISCUSSION.}

Dr. J. L. Morse: It seems to me that pleural adhesions as the result of pleurisy, or possibly empyema when he was two years old, at the time of the pneumonia, might account for many of the symptoms and physical signs. It is very hard in these cases to distinguish between trouble in the lung and trouble in the pleura.

Dr. A. H. Wentworth: I would like to ask about the temperature at the time the child was four years old. I think that an encapsulated empyema might have caused the present condition. Empyemas are common after pneumonia. I do not say that tuberculosis could not have been superimposed on a chronic indurative process in the lung, but I do not believe there is proof that tuberculosis caused the induration. I should like to ask who found the tubercle bacilli. Pulmonary tuberculosis in a child rarely disappears as quickly as this appeared to do.

Dr. Fairbanks, in reply to Dr. Morse and Dr. Wentworth, said: In regard to the pleural adhesions which Dr. Morse speaks of, it is a certainty that there are pleural adhesions in this case. There practically always are in these cases.

In regard to whether the symptoms in this case were caused by the adhesions, $I$ think it is a question as to the degree of the process. It is a question also of the impression the child has given one in watching him through these years. I should say that pleural adhesions, even with that great thickening which you sometimes see post-mortem, would hardly cause as marked a condition as this is, and I hardly think that the hypertrophy of the well lung would be as marked if it were merely secondary to simple retraction from pleural adhesions in the other lung. I simply want to give that as my personal opinion and not set it down as a law, by any means. I do not think that the pleurisy in this case was primary. These cases of interstitial induration are much in dispute. Some claim that the pleurisy starts first, that it very often is a pleurisy with adhesions and thickening and that the induration of the lung is secondary. Fraenkel takes the opposite stand to this and thinks that the majority of the cases are primarily in the lung and that the pleuritic change is secondary. I cannot say how much pleurisy there is in this case, but there is some, undoubtedly.

Now in regard to the temperature. During the first three or four months he was under observation he ran a temperature varying from $99^{\circ} \mathrm{F}$. to $100^{\circ} \mathrm{F}$., never, I think, over that, but two years later, when six years old, during the bronchopneumonia, he ran a temperature of $104^{\circ} \mathrm{F}$. The temperature has been taken in his case perhaps thirty-five or forty times, a rough estimate, and it has never been, except as stated above, over $101^{\circ} \mathrm{F}$.

The tubercle bacilli were found by the board of health, and also by myself, and I feel sure that there was no mistake, and the board of health confirmed my findings independently.

Since the presentation of the case and the above discussion, the $x$-ray plate, from which the accompanying photograph is taken, was obtained. This confirms the suppositions based on physical diagnosis and shows well the contracted condition of the left half of the thorax. The irregular interference with the passage of the ray, shown by the mottled condition of the left side of the skiagraph, it seems reasonable to
It is only in the extreme lower part of the left thorax that the uniform character of the shadow suggests pleural thickening. The lowering of the left shoulder as well as the scoliosis is well shown, although the degree of deformity in the child is much more pronounced than appears in the photograph. The hypertrophy of the right lung is excellently shown.

THE ALOIN OR GUAIAC TEST FOR BLOOD DEPENDS SOLELY UPON THE IRON CONTAINED IN ITS HEMOGLOBIN.*

\footnotetext{
BX WILLIAM F. WHITNEY, M.D.
}

IN 1861, Van Deen first called attention to the fact that if a tincture of gum guaiac is mixed with a solution of blood coloring matter and then a fluid carrying loosely combined oxygen is added, a deep blue color is at once developed, fading away after a short time.

Aloin is another substance which gives a color reaction in the same way, only it is red instead of blue. This was first brought into notice by Klunge about twenty years later.

Because of their delicacy and ease of application, these two tests are employed in the preliminary examination of suspected blood stains. But their real value is chiefly negative, as it has been found that there are many other substances which give the same reaction. Therefore, if a suspected stain reacts with guaiac, or aloin, further tests must be made to prove that it is blood, while if it does not react it can be surely stated, without further testing, that it is not blood, at least, does not contain normal blood coloring matter.

The substances which have been found to react are iron and many of its salts, manganese, copper, gold and platinum salts, extracts of some plants, watery extract from leather or even flannel, and some kinds of filter paper.

Of these iron at once attracts attention since it is one of the constituents of the normal blood. Before, however, taking up that complicated combination, it would be well to try the delicacy of the reaction with the metal itself and some of its simpler salts.

I have chosen aloin rather than guaiac with which to show you these tests as it has the advantage of being somewhat soluble in water, while guaiac is not, and furthermore, the color which is produced does not fade so quickly.

First let us take the pure metal. A steel needle is broken into small pieces and one of these is placed in a porcelain dish with a little distilled water and allowed to stand for a few minutes. Then a little powdered aloin is stirred in, until the water assumes a light yellow color. A few drops of peroxide of hydrogen are added and a reddish color is soon seen to develop, most strongly marked at the broken ends of the needle or at any point where the polish has been removed.

Reduced iron and iron rust will act in a similar manner.

Of the salts of iron, the perchloride is the most

* Read before the Massachusetts Medico-Legal Society at Boston, on June 11, 1907 . 